combination of these 2 is highly undesirable, although this did not have clinical consequences for this patient. Therefore, we propose that when a large asymmetry in NIRS values is noticed during ACP, a right ventricle to pulmonary artery shunt deserves consideration to avoid risk of cerebral damage of the right hemisphere.

\section{References}

1. McQuillen PS, Barkovich AJ, Hamrick SE, Perez M, Ward P, Glidden DV, et al. Temporal and anatomic risk profile of brain injury with neonatal repair of congenital heart defects. Stroke. 2007;38:736-41.
2. Ohye RG, Goldberg CS, Donohue J, Hirsch JC, Gaies M, Jacobs ML, et al. The quest to optimize neurodevelopmental outcomes in neonatal arch reconstruction: the perfusion techniques we use and why we believe in them. J Thorac Cardiovasc Surg. 2009;137:803-6.

3. Kimatian SJ, Myers JL, Johnson SK, Suominen PK. Transcranial Dopplerrevealed retrograde cerebral artery flow during Norwood 1 operation. ASAIO J. 2006;52:608-10.

4. van Kooij BJ, Hendrikse J, Benders MJ, de Vries LS, Groenendaal F. Anatomy of the circle of Willis and blood flow in the brain-feeding vasculature in prematurely born infants. Neonatology. 2010;97:235-41.

5. Andropoulos DB, Diaz LK, Fraser CD Jr, McKenzie ED, Stayer SA. Is bilateral monitoring of cerebral oxygen saturation necessary during neonatal aortic arch reconstruction? Anesth Analg. 2004;98:1267-72.

\title{
Composite reconstruction with cryopreserved fascia lata, single mandibular titanium plate, and polyglactin mesh after redo surgery and radiation therapy for recurrent chest wall liposarcoma
}

\author{
Gaetano Rocco, MD, FRCSEd, Flavio Fazioli, MD, Rocco Cerra, MD, and Rosario Salvi, MD, Naples, Italy
}

Repeated chest wall resections after irradiation often mandate individualized reconstructive strategies. We report a case of a simplified reconstruction with a combination of materials recently used by thoracic surgeons because of their favorable biologic characteristics and user friendliness during implantation.

\section{CLINICAL SUMMARY}

A 68-year-old woman was referred from another institution for a biopsy-proved recurrent G2 liposarcoma of the lower right hemithorax at the level of the eighth to ninth ribs after prior incomplete surgical removal of the myocutaneous layers and subsequent irradiation (70 Gy). Redo surgical intervention was performed by removing en bloc the involved chest wall, making sure to maintain the myocutaneous resection line at $5 \mathrm{~cm}$ from the palpable tumor mass. Reconstruction was done by using a cryopreserved fascia lata homograft anchored to the remaining rib segments. In addition, a single mandibular titanium plate (Synthes, Solothurn, Switzerland) was used to bridge the bony defect (Figure 1, A

From the Department of Thoracic Surgery and Oncology, Division of Thoracic Surgery, Services of Orthopaedic and Plastic Surgery, National Cancer Institute, Pascale Foundation, Naples, Italy.

Disclosures: Authors have nothing to disclose with regard to commercial support. Received for publication May 15, 2010; accepted for publication June 28, 2010; available ahead of print Aug 5, 2010.

Address for reprints: Gaetano Rocco, MD, FRCSEd, Via Terminio 1 Serino (Avel-

lino) 83028 Italy (E-mail: Gaetano.Rocco@btopenworld.com).

J Thorac Cardiovasc Surg 2011;141:839-40

$0022-5223 / \$ 36.00$

Copyright (c) 2011 by The American Association for Thoracic Surgery

doi:10.1016/j.jtcvs.2010.06.050 and $B$ ). The shorter arm of this single plate was fixed with locking screws to the posterior segments of the uninvolved 2 lowermost ribs while the longer arm was anchored to the remaining anterolateral segment of the eighth rib. Given the absence of the overlying muscle and to avoid direct friction of the plate on the approximated skin edges, a polyglactin mesh was sutured to the muscle edges to cover the plate (Figure 1,C). The postoperative course was uneventful, and the patient was discharged home 7 days after the operation. At the 3-month follow-up, the chest radiograph showed a satisfactory outcome (Figure 1, D).

\section{DISCUSSION}

Full-thickness chest wall defects after redo operations and radiation treatment require reconstructive materials warranting structural stability, easy incorporation into the host, and resistance to infection. ${ }^{1,2}$ In this patient, under standard circumstances, a polytetrafluoroethylene patch or a methyl methacrylate sandwich would be used to provide coverage and stabilization with satisfactory results, ${ }^{1}$ although these materials would not be incorporated and remain at risk for subsequent infection. ${ }^{1,2}$ In addition, the interposition of viable myocutaneous flaps would have been necessary to protect the superficial dermocutaneous layers.

The use of titanium plates is gaining popularity for the ability to shape them to fit both in the rib or the sternal position, thereby conferring enhanced stability, and to adapt to the desired geometric configuration. ${ }^{3}$ Recently, several titanium plates were used in conjunction with polytetrafluoroethylene patches in the reconstruction of significant lateral 


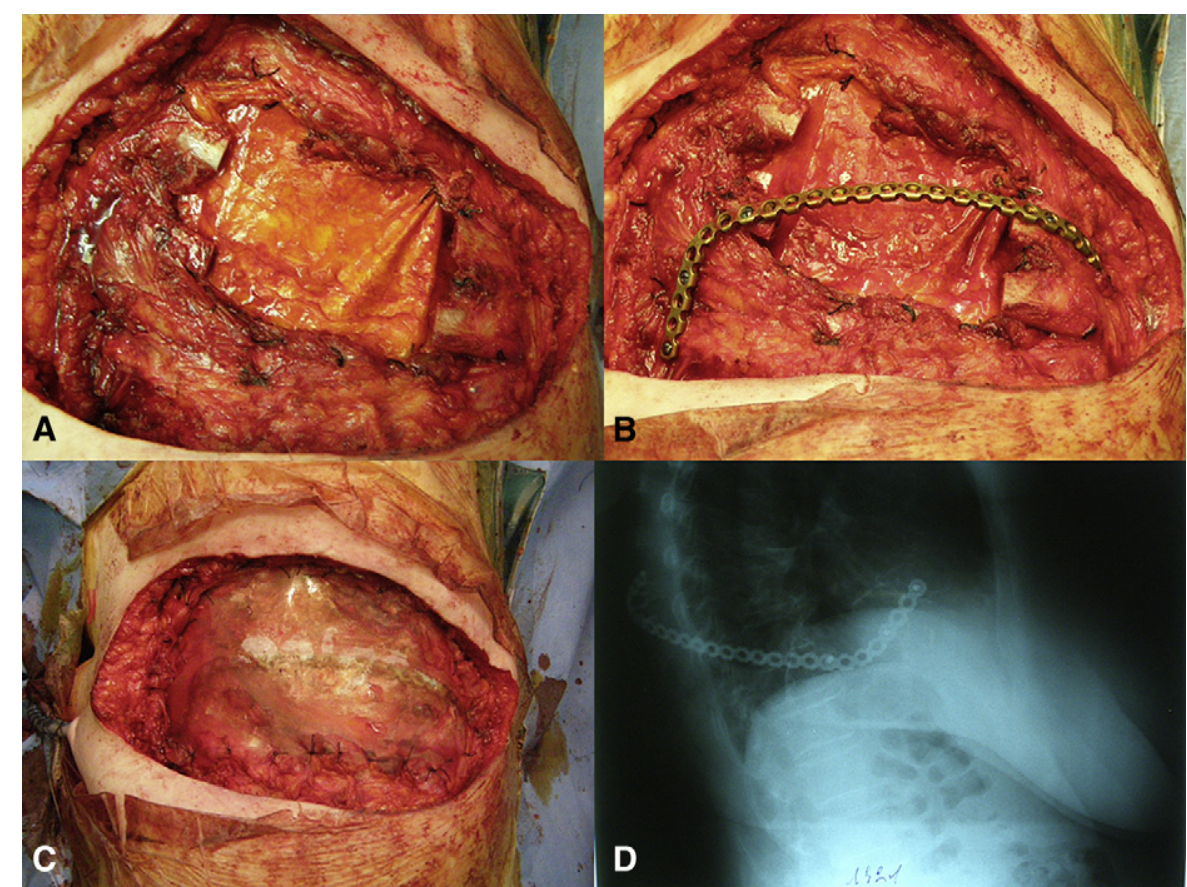

FIGURE 1. The cryopreserved fascia lata homograft tightly covers the chest wall defect (A). The mandibular titanium plate is applied (B) and covered with a polyglactin mesh (C). A follow-up chest radiograph is obtained at 3 months (D).

defects. ${ }^{4}$ Resorting to a single mandibular plate allows for the bridging of the remaining rib segments at various levels, thereby avoiding the need for (and costs of) multiple straight plates. On the other hand, cadaveric cryopreserved homografts represent an ideal, theoretically limitless source of materials for chest wall replacement. ${ }^{2}$ In this setting, pedicled and nonpedicled autologous fascia lata grafts have also been used for chest wall reconstruction, despite the attendant second wound and donor site-related morbidity. ${ }^{5}$ The combination of a cryopreserved cadaveric fascia lata to protect the lung and avoid herniation, a single mandibular titanium plate applied to stabilize the chest wall after multiple rib resection, and a polyglactin mesh to avoid friction with the overlying skin seemed to respond to our preoperative requirements. We believe this simplified surgical technique could be a useful addition to the surgical armamentarium to address challenging chest wall scenarios.

\section{References}

1. Weyant MJ, Bains MSD, Venkatraman E, et al. Results of chest wall resection and reconstruction with and without rigid prosthesis. Ann Thorac Surg. 2006;81: 279-85.

2. Rocco G, Fazioli F, Scognamiglio F, et al. The combination of multiple materials in the creation of an artificial anterior chest cage after extensive demolition for recurrent chondrosarcoma. J Thorac Cardiovasc Surg. 2007;133:1112-4.

3. Marulli G, Hamad AM, Schiavon M, Azzena B, Mazzoleni F, Rea F. Geometric reconstruction of the right hemi-trunk after resection of giant chondrosarcoma. Ann Thorac Surg. 2010;89:306-8.

4. Pompili C, Brunelli A, Xiume' F, Sabbatini A. Chest wall reconstruction with a titanium rib bridge for post-traumatic parietal hernia. Eur J Cardiothorac Surg. 2010;37:737.

5. Murakawa T, Nakajima J, Maeda K, Tanaka M, Takamoto S. Reappraisal of fascia lata grafts for reconstruction of chest wall defects. Asian Cardiovasc Thorac Ann. 2002;10:285-6. 